the appendage biopsy results failed to give any indication of prognosis. In two of our cases the comment had been made at the first operation that "it would not be surprising if the rheumatic process were still active," and in these two cases the appendage biopsies showed numerous Aschoff bodies suggesting continued rheumatic activity. Another patient had several attacks of subacute rheumatism in the interval between operations.

Logan et al. (1962) found that $36 \%$ of patients who had cusps completely separated anteriorly and posteriorly developed restenosis after an interval of more than five years.

This was not the experience of Belcher $(1960,1962)$, who found that only $4 \%$ of patients who had a complete split of both commissures had restenosed when followed up for eight years. Furthermore, he is convinced that an inadequate first operation is of prime importance in causation, and he has not known of restenosis in any case in which he has used the dilator.

Can these diverging views be reconciled? Before expressing an opinion several variable factors require to be considered, such as the critical assessment of operation notes, completeness of follow-up studies, criteria accepted for the diagnosis of restenosis, and the time interval between operations.

Our findings tend to support those of Belcher (1960, 1962). In 27 of the 32 cases the primary operation was undoubtedly inadequate. No case had a complete separation of both anterior and posterior commissures. We believe that after every valvotomy there is some re-fusion at the outer ends of the commissurotomy, and this is certain to occur. It would seem logical that a poor split followed by this inevitable restenosis would in most cases lead to a recurrence of symptoms. On the other hand, a similar amount of restenosis in a case having had a wide split would not decrease the size of the valve orifice by the same proportion. When we examined the decrease in valve size in the interval between operations we found that it amounted to 1 to $1.5 \mathrm{~cm}$. in $23(72 \%)$ cases, $2 \mathrm{~cm}$. in $4(12.5 \%), 2.5 \mathrm{~cm}$. in $4(12.5 \%)$, and $3 \mathrm{~cm}$. in one case $(3 \%)$. This possibility of inevitable reduction in value size, say from 1 to 1.5 cm., would explain our finding that stenosis recurred most often in cases in which the primary valvotomy was inadequate. When restenosis occurred in patients believed to have had a reasonable split the process had been more extensive ( 2 to $3 \mathrm{~cm}$.).

Is this theory of inevitable partial re-fusion compatible with the common experience that many patients who have had an inadequate valvotomy make good progress and have no recurrence of symptoms for many years? We believe that in some cases it is possible that a degree of restenosis may occur without giving rise to symptoms, for it must be borne in mind that in some patients the actual valve stenosis may be the main or only feature, while in others the effects of prolonged back pressure and myocardial damage are so extensive as to bear a much greater influence on the result of any valvotomy carried out. In other words, there are two groups of patients-the one in which the size of the valve orifice is the dominant feature, and the one in which other factors are of equal or of more importance. Wood (1954) stressed that in the latter group the size of the valve orifice in mitral stenosis bore no relation to the liability to develop symptoms such as pulmonary oedema and auricular fibrillation.

\section{Summary}

In a series of 270 valvotomies the case records of 32 patients requiring reoperation have been reviewed.

In more than half the cases deterioration occurred within the first two years after operation. In several cases this deterioration was not sufficient to warrant operation for a further two years.

In all cases the valve orifice at the second operation was smaller than at the conclusion of the first, and in 11 the valve size was smaller than before splitting at the first.

The primary commissurotomy was regarded as inadequate in 27 cases.

It is suggested that after mitral valvotomy all cases develop some degree of re-fusion, and in consequence recurrence of symptoms is most likely in those that had an inadequate valvotomy.

We wish to acknowledge details of reoperations provided by Professor W. A. Mackey, Glasgow ; Mr. B. B. Milstein, Papworth; Dr. R. Robertson, Vancouver; and Mr. Vernon Thompson, London. We also wish to acknowledge secretarial assistance given by Miss E. McLean.

\section{REPERENCES}

Belcher, J. R. (1960), Lancet, 1, 181.

Belcher, J62). Ibid., i, 694.

Logan, A., Lowther, C. P., and Turner, R. W. D. (1962). Ibid.,

Lowther, C. P., and Turner, R. W. D. (1962). Brit. med. J., 1, 1027 .

Wood, P. (1954). Ibid., 1, 1051, 1113.

\section{CUSHING'S SYNDROME AND SKIN PIGMENTATION}

BY

\author{
A. STUART MASON, M.D., M.R.C.P. \\ Consultant Endocrinologist, the London Hospital \\ AND \\ D. GREENBAUM, M.B., M.R.C.P. \\ Senior Medical Registrar, the London Hospital
}

The role of the pituitary in Cushing's syndrome has been debated since the syndrome was first described (Cushing, 1932). Adenoma formation in the pituitary, found in 34 out of 58 cases collected by Knoulton (1953), is no proof of excess endocrine activity, as such tumours are not uncommon in the absence of adrenal dysfunction (Susman, 1935). A strong pituitary stimulus is suggested by the manner in which minute adrenal fragments may hypertrophy after adrenalectomy (Mason, 1957). Direct evidence of pituitary hyperfunction was provided by Clayton (1958) and Davies et al. (1960), who recorded high levels of plasma A.C.T.H. in Cushing's syndrome, although Paris et at. (1954) had previously reported negative results.

The relationship of Addisonian pigmentation to pituitary activity was demonstrated by Sulman (1956), who found raised concentrations of a melanophorestimulating hormone (M.S.H.) in Addison's disease and also in some cases of Cushing's syndrome. The close similarity of M.S.H. and A.C.T.H. makes it impossible to determine the contribution of each hormone to the 
total melanophore-stimulating activity present in blood (Harris and Lerner, 1957 ; Karkun et al., 1960). Intense Addisonian type pigmentation has been recorded in untreated Cushing's syndrome associated with large pituitary tumours (Marks, 1959) and with similar tumours apparently arising after adrenalectomy (Nelson et al., 1958 ; Bayliss, 1959). Skin pigmentation appears to be a clinical sign of pituitary overactivity.
This paper records the occurrence of pigmentation during the development or treatment of Cushing's syndrome and in the absence of adrenal insufficiency. Seven patients of a series of 21 who survived adrenalectomy for at least one year developed some pigmentation. One case presented with pigmentation and active Cushing's syndrome. Details of the eight cases are given in the Table.

Details of Cases

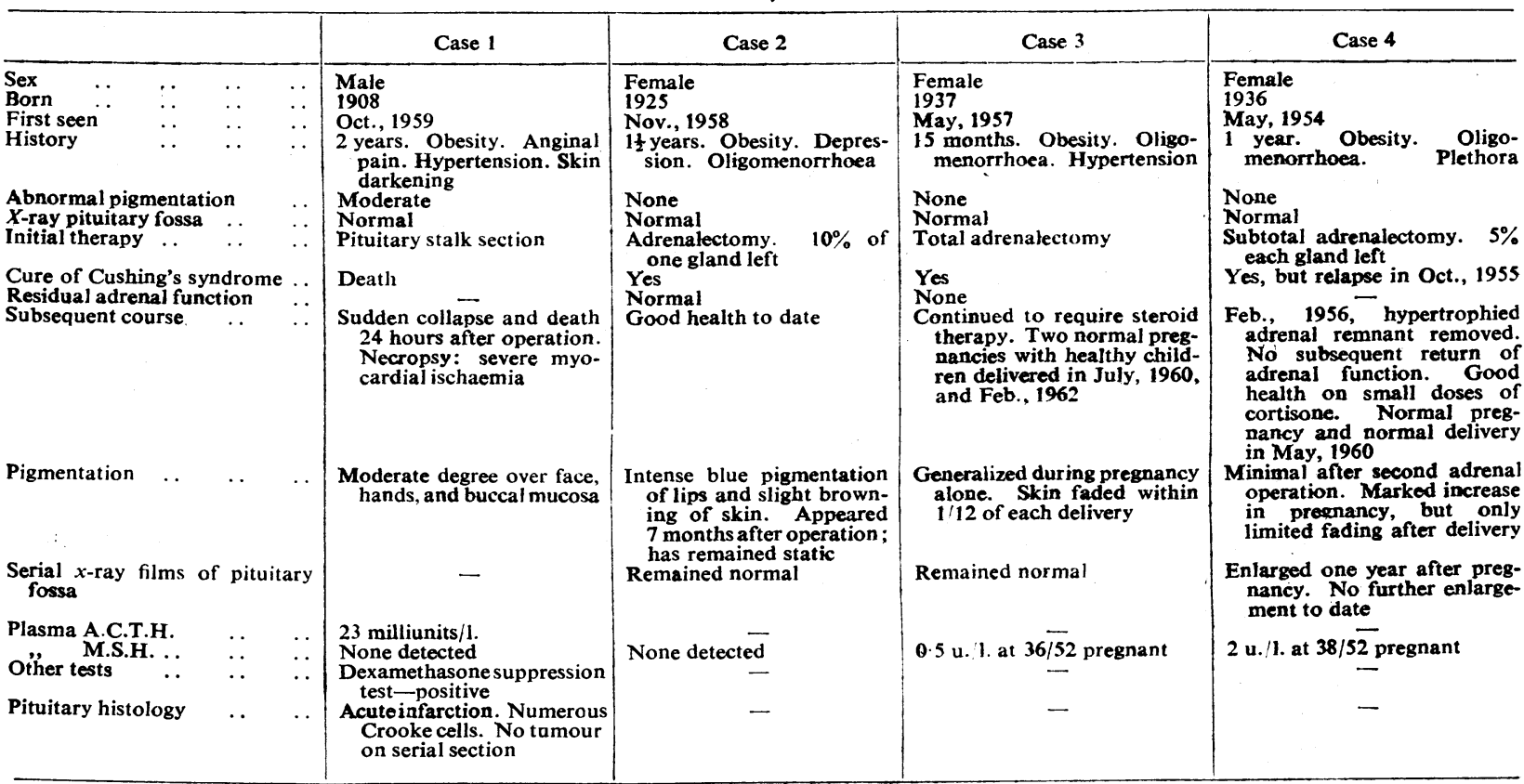

Details of Cases-continued

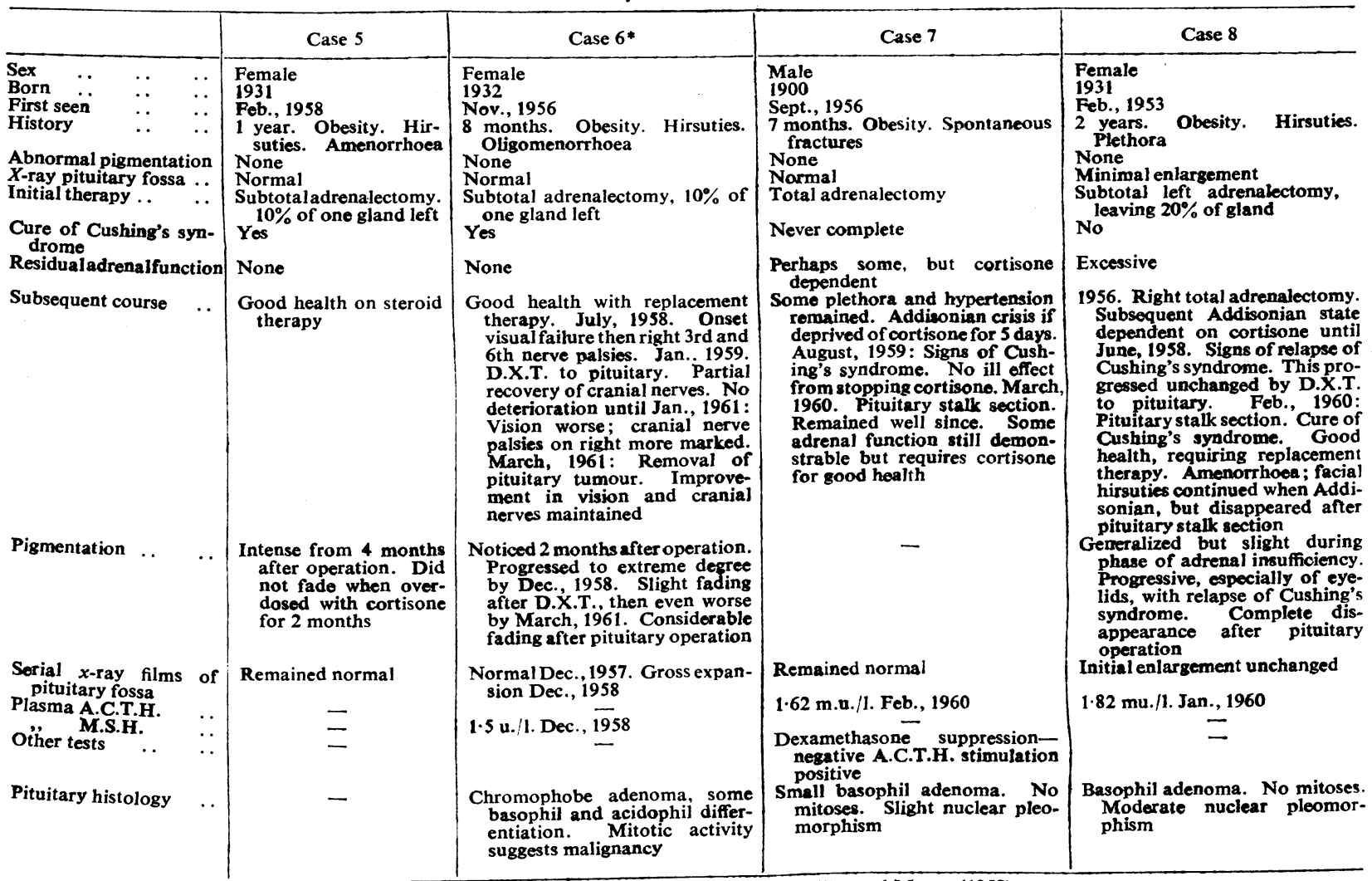




\section{Discussion}

Plasma M.S.H. levels were measured in five patients : in three it was raised, and two of these were deeply pigmented. Plasma A.C.T.H. assays were performed in three cases, increased levels being found in all three. The highest value for plasma A.C.T.H. was found in a patient whose plasma M.S.H. was normal.

Hypophysectomy abolished the pigmentation in two patients. Addisonian skin pigmentation proved to be a reliable clinical guide to pituitary overactivity.

Skin pigmentation in the presence of adrenal hyperfunction was observed in three patients. The degree of pigmentation was not as intense as that observed in the four patients who became pigmented in the absence of functioning adrenal tissue. Localized pigmentation developed in only one patient whose adrenal function had been restored to normal by subtotal adrenalectomy. The persistence of pigmentation despite adequate steroid replacement therapy was in marked contrast to Addison's disease, in which pigmentation fades as replacement therapy becomes effective. The normal inhibiting effect of glucocorticoids on pituitary activity appears to be altered in Cushing's syndrome, but the limitation of pigmentation in the presence of adrenal hyperfunction suggests that the homoeostatic mechanism is insensitive rather than inactive. Williams et al. (1961) found that, for any blood level of hydroxycorticoids, the blood level of A.C.T.H. was higher in patients adrenalectomized for Cushing's syndrome than in patients with Addison's disease. Dexamethasone given in a dose sufficient to suppress normal pituitary function failed to suppress this activity in Cushing's syndrome, but suppression could be achieved by greatly increasing the amount of dexamethasone (Liddle, 1960).

Three pituitary tumours were detected in this series. Two were small non-invasive basophil adenomas associated with recurrent adrenal hyperfunction. One remained the same size for seven years. The third tumour, a chromophobe adenoma, grew rapidly and became locally invasive after the patient had been adrenalectomized. The speed of tumour growth appears to be slowed by the presence of excessive glucocorticoids and to accelerate if the glucocorticoid concentration is normal or low (Salassa et al., 1959 ; Shrank and Turner, 1960).

Cushing himself noted that the small pituitary tumours associated with his syndrome were composed of basophil cells, but Marks (1959) pointed out that the large tumours, more rarely found, were usually chromophobe in type. Such chromophobe adenomas are very rich in A.C.T.H. (Bayliss, 1959 ; Montgomery et al., 1959) and also differ from other chromophobe tumours in their propensity for local invasion causing cranial nerve palsies (Salassa et al., 1959). Pituitary tumours in Cushing's syndrome maintain or increase their endocrine activity as they grow larger, but the cell type changes from basophil to chromophobe.

The growth of a pituitary adenama, probably chromophobe and potentially malignant, should always be suspected if deep pigmentation is found in a patient with Cushing's syndrome, particularly if adrenalectomy has been performed. The small adenoma of basophil cells may not be detectable by radiological means, but it is suggested from the data on Case 7 that failure of dexamethasone to suppress adrenal function and successful adrenal stimulation by A.C.T.H. may be an indication of pituitary tumour formation.

The evidence cited above suggests that Cushing's syndrome in the absence of an adrenal tumour is caused by pituitary overactivity, which may be associated with tumour formation. The mechanism involved is the homoeostatic link between pituitary and adrenals; this link is deranged but not disrupted. Since there is ample experimental evidence, reviewed by Sayers (1960), to indicate that adrenal-pituitary homoeostasis is integrated by the hypothalamus, it is probable that Cushing's syndrome is primarily a disturbance of the hypothalamus, a view advanced by Heinbecker in 1944 . Tumour growth in the pituitary does not argue against this hypothesis, as the limitation of such growth by excessive adrenal function indicates that the pituitary is not autonomous in terms of cell grawth. Moreover, the hypothalamus has been shown to be essential for the histological differentiation of pituitary cells (Nikitovitch-Winer and Everett, 1958).

The evidence of pituitary overactivity in Cushing's syndrome and the occasional rapid growth of potentially malignant pituitary tumours after adrenalectomy call for a reappraisal of adrenalectomy as the treatment of choice. Destruction of the pituitary can be accomplished surgically or by radiation. In this series pituitary stalk section with partial removal of tumour tissue has proved effective and is a less severe surgical procedure than complete removal of the gland. Deep $x$-ray therapy to the pituitary has, in our experience, proved to be of little value in the treatment of Cushing's syndrome. It also failed to halt the growth of the large pituitary tumour in Case 6, although there was a temporary improvement. Implantation of radioactive materials into the pituitary offers a more reliable means of pituitary destruction, with minimal disturbance of the patient (Fraser and Joplin, 1961). However, pituitary ablation by any means causes a widespread disorder of endocrine function. The successful pregnancies recorded in this series would not have occurred if the patients had been treated by pituitary ablation instead of adrenalectomy. A therapeutic attack on the pituitary is recommended if the patient has Addisonian type pigmentation or any evidence, clinical or radiological, of a pituitary tumour. A relapse of Cushing's syndrome after initial cure by radical adrenalectomy also suggests that treatment should be directed to the pituitary rather than to the adrenal remnant.

\section{Summary}

Case records are given of eight patients with Cushing's syndrome who developed pigmentation at some stage of their disease and in the absence of adrenal insufficiency.

The presence and degree of pigmentation was found to be a reliable clinical guide to pituitary overactivity in terms of A.C.T.H. and M.S.H. secretion.

Pituitary tumours were demonstrated in three patients. The small tumours were benign functioning basophil tumours, but the one rapidly growing tumour, identical to others already recorded, was large, malignant, and chromophobe in type.

The rate of tumour growth and pituitary overactivity is diminished by excessive plasma hydroxycorticoid levels and enhanced when these levels are maintained at normal concentrations. 
It is concluded that Cushing's syndrome is due to pituitary overactivity which is prompted by a hypothalamic disorder that disturbs rather than disrupts the normal homoeostatic link between pituitary and adrenal.

We are grateful to Professor I. Doniach for his reports on pituitary histology; to Drs. Clayton and Davies for A.C.T.H. assays; and to Dr. Mitchell for M.S.H. assays. We thank the consultant staff of the London Hospital for their co-operation, in particular Mr. D. W. C. Northfield for carrying out the neurosurgical procedures and for his continued interest.

\section{REFERENCES}

Bayliss, R. I. S. (1959). Proc. roy. Soc. Med., 52, 256

Clayton, B. E. (1958). Ibid., 51, 558

Cushing, H. (1932). Bull. Johns Hopk. Hosp., 50, 137.

Davies, B., Currie, A. R., and Symington, T. (1960). Quoted by T. Symington in Modern Trends in Endocrinology, edited by H. Gardiner-Hill, 2nd series, p. 5. Butterworths, London. 1961 .

Fraser, R., and Joplin, G. F. (1961). Ibid., p. 69.
Harris, J. I., and Lerner, A. B. (1957). Nature (Lond.), 179, 1346 .

Heinbecker, P. (1944). Medicine (Baltimore), 23, 225.

Karkun, J. N. Landgrebe, F. W., Main, R. A., and Mitchell, G. M. (1960). J. Physiol. (Lond.), 152, 459.

Knowlton, A. I. (1953). Bull. N.Y. Acad. Med., 29, 441.

Liddle, G. W. (1960). J. clin. Endocr., 20, 1539.

Marks, V. (1959). Acta endocr. (Kbh.), 32, 527.

Mason, A. S. (1957). Proc. roy. Soc. Med., 50, 766.

Montgomery, D. A. D., Welbourn, R. B., McCaughey, W. T. E. and Gleadhill, C. A. (1959). Lancet, 2, 707.

Nelson, D. H., Meakin, J. W., Dealy, J. B., Matson, D. D. Emerson, K., and Thorn, G. W. (1958). New Engl. J. Med., 259, 161 .

Nikitovitch-Winer, M., and Everett, J. W. (1958). Endocrinology, 63, 916.

Paris, J., Üpson, M. Sprague, R. G., Salassa, R. M., and Alberta, A. (1954). J. clin. Endocr., 14, 597.

Salassa, R. M., Kearns, T. P., Kernohan, J. W., Sprague, R. G. and McCarty, C. S. (1959). J. clin. Endocr., 19, 1523.

Sayers, G. (1960). Abstr. Symp. Ist int. Congr. Endocr., p. 25 Schiller, K. F. R., and Mason, A. S. (1959). Proc. roy. Soc. Med. 52,1054

Shrank, Ä B., and Turner, P. (1960). Brit. med. J., 1, 849.

Sulman, F. G. (1956). J. clin. Endocr., 16, 755.

Susman, W. (i935). Brit. J. Surg., 22, 539.

Williams, $\dot{W}$ C., lsland, D., Öldfield, R. A. A., and Liddle, G. W. (1961). J. clin. Endocr., 21, 426 .

\title{
REDUCING RADIATION HAZARDS IN THE RADIUM WARDS
}

PATRICIA HOWES, S.R.N., S.C.M.

\author{
University College Hospital, London
}

Many authors have reported measurements of radiation dose received by hospital personnel, and some of them (Mayneord, 1951 ; Leetz, Masch, and Mohr, 1958; Clarke, 1960 ; Quimby, 1960 ; Zeitz and Zolg, 1960 ; Koren, Maudal, Flatby, and Berteig, 1960 ; Ellis 1961) have found, as we have, that one of the most difficult aspects of radiation safety in a hospital is the protection of ward nursing staff during the therapeutic use of radium. Large quantities of radioactive material are used, and such patients must receive nursing attention many times, under circumstances which prevent shielding according to laboratory standards.

Substantial radiation doses may be received in such circumstances, and official reports such as the Code of Practice (Ministry of Health, 1957) or the Recommendations of the International Commission on Radiological Protection (1960) give little help in reducing them.

During the past few years we have conducted a detailed study of this problem as it affects a ward in this hospital, where most gynaecological radium treatments are carried out.

\section{Ward Routine}

Ward nurses need to be near to the radium patient for the following procedures : $(a)$ in theatre; during transfer of the patient to the ward, and during postoperative recovery; during removal of the radium at the end of treatment. (b) During radiographic localization. (c) During bed-making, washing, and care of pressure areas. (d) Attention to catheter, and emptying drainage. (e) During the taking of temperature, bloodpressure, pulse, and respiration rates; locker inspection. $(f)$ Giving fluids and meals. (g) In emergencies such as vomiting and renewal of the catheter.

In the 10-bedded ward during the period covered by this survey about 60 radium treatments were given. It is not usual for more than one patient to be under treatment with radium at a time, but the precautions discussed below will still be applicable, mutatis mutandis.

Only on rare occasions in this ward, even at the start of the survey, has any member of the nursing staff received a dose as high as $300 \mathrm{mr}$ in a week, or a total exceeding $1 \mathrm{r}$ in 13 weeks. Even so, doses received during the nursing of radium patients were higher than those received by other nursing staff, and therefore (following the Recommendations of the I.C.R.P. that all doses be kept as low as possible) efforts have been made to reduce them.

The radiation received by the staff as a whole will depend partly on the nursing attention required by the patient, partly on the techniques used, and partly on the amount of radium inserted and the duration of treatment

In order to eliminate these last two variables we have expressed the radiation received as milliroentgens per 1,000 milligram-hours of radium treatment; the total dosage received by the nursing staff during a period of over three years is shown, quarter by quarter, in Fig. 1. The radiation received has been evaluated separately for the sister in charge of the ward, her deputy (a staff nurse), and junior nurses, and these are shown in Fig. 2. A steady reduction is apparent, as is made clear in Table I.

Expressing doses in $\mathrm{mr} / 1,000 \mathrm{mg}$. hours of radium treatment is of little value ordinarily, but it does enable

TABLE I.-Radiation Records on a Radium Ward for a Period of Over Three Years (Doses in Milliroentgens per Thousand Milligram-hours of Radium Treatment)

\begin{tabular}{|c|c|c|c|c|}
\hline \multirow{2}{*}{$\begin{array}{l}\text { Measure- } \\
\text { ments } \\
\text { Made in }\end{array}$} & \multirow{2}{*}{$\begin{array}{c}\text { Total } \\
\text { Radiation } \\
\text { received by } \\
\text { Nursing Staff }\end{array}$} & \multicolumn{3}{|c|}{ Radiation received per Person } \\
\hline & & Sister & Staff Nurse & Junior Nurses \\
\hline $\begin{array}{l}1958 \ldots \\
1959 \ldots \\
1960 \ldots \\
1961 \ldots\end{array}$ & $\begin{array}{r}213 \\
187 \\
161 \\
78\end{array}$ & $\begin{array}{r}22 \\
12 \\
13 \\
7\end{array}$ & $\begin{array}{l}32 \\
25 \\
15 \\
14\end{array}$ & $\begin{array}{l}29 \\
21 \\
16 \\
10\end{array}$ \\
\hline
\end{tabular}

